\title{
Research on Application of Information Technology in Sports Training
}

\author{
Hong Zhang \\ School of physical education \& sports science, Guangzhou, Guangdong, 510631
}

Keywords: Physical Education, Information Technology, Sports Training.

\begin{abstract}
With the continuous improvement of social level, the application of information technology has been gradually taken seriously. In this paper, the application of information technology in the current sports training in the application of research should be from a different perspective on the impact of information technology on contemporary sports training which have. And also pointed out that in the contemporary sports training in the use of information technology, the advantages of what, how to effectively use information technology to serve today's development of physical education is the focus of the current sports career.
\end{abstract}

\section{Introduction}

With the continuous development of network technology, in the current society has entered the network as the core of the information age. And the development and utilization of information technology has gradually penetrated people's lives in all aspects of people's way of life, mode of production, working methods and even the way of thinking are being subtle changes. The application of information technology to modern education is already a very common thing. As a diversified discipline that integrates knowledge transfer, skill training and physical exercise, sports has become one of the indispensable tools for the training of physical education. And with the information technology in the development of physical education in the footsteps of faster and faster, for China's current sports development has an effective role in promoting.

\section{The overall development of information technology in the field of sports}

With the continuous progress of society, China's attention to the cause of education is also getting higher and higher. And with the advent of the information age, how to rational use of modern information technology, making our teaching more scientific, is the tireless efforts of today's educators to pursue the goal. With the modern education in modern information technology more and more widely, to educators brought great convenience. For example, the use of multimedia, video, recording trinity of the use of modern technology system. Through the use of training content and teaching scene organically combined, so that students have an immersive feeling, not only can cause students' interest, but also to show the level of physical education in the teaching level, to help students develop intelligence. This use of modern technology scene reproduction, making the original boring learning becomes relaxed and happy, so as to effectively mobilize the enthusiasm of students, students to develop practical ability. And compared to the traditional sports teaching point of view, the traditional sports teaching boring monotonous, resulting in students of sports training had a negative mood [1]. And the use of practical training can be: teachers use modern information technology to record some of their students are more interested in the game and training clips, through comparison with other, found themselves in shortcomings, but also able to More image to help students learn some in the teaching of physical education more difficult to understand the point of view, so as to improve the quality of teaching. According to the physical education in primary and secondary school physical education survey, we found that the audio-visual media in the multi-channel to provide information, adjust the temporal and spatial changes, intuitive and truly reflect the phenomenon of things and changes in the movement characteristics is obviously due to 
the traditional simple vision and Auditory media. And in the actual training, this kind of audio-visual multimedia information technology, can mobilize the students' audio-visual function, can significantly improve the efficiency of student learning and promote their athletic skills to enhance [2].

In China's current social environment, according to the characteristics of information technology in the application of physical education, information technology in the field of sports also has a broad market and development prospects for our sports educators is also an important theoretical significance and Practical value. The development of information technology has provided the basic support for the development of the whole sports cause in our country, and the multidisciplinary theoretical research in the training, psychology, biology and nutrition, which is included in it, has also promoted the improvement of teaching and training achievement And the development of information technology to promote each other.

\section{The application of information technology in sports training process}

With the application of information technology in China's sports education more and more widely, its position in physical education is also more and more important. Information technology brought about by the diagnosis of motor technology, more accurate analysis, which is more conducive to students of sports learning, improve sports performance [3].

In the traditional physical education training, students have sports skills learning and improvement mainly from teachers and students of their own experience. In order to be able to in sports training, more prominent students of the advantages and weaknesses, you can use information technology to students of sports training into a video, and then enter the action one by one analysis. But also can be used for the training of students using high-tech computer data collection, so as to help teachers manage students daily training hee, so teachers can be based on these information, effective training direction for students and training characteristics to develop appropriate training programs, To assist in training and simulating the effects of movement. And this is to achieve the movement to find the process to conduct a comprehensive monitoring, in order to achieve the purpose of student training results of perfection. And this kind of computer-aided training system involves the sports training, sports medicine, biomechanics and other aspects of scientific principles, therefore, through the system can effectively improve the efficiency and training in the daily training level, so as to avoid the traditional dependence Experiential training brought about by the defects [4].

The development of information technology can effectively combine the teaching information such as text, pattern and sound, and the teaching method is not limited by time and space, so that the teaching can be carried out directly to the students, so as to realize the teaching information, On the one hand, it can help students to take the initiative to observe, test, guess and solve the problem, and on the other hand is to be able to facilitate the implementation of student status, to help teachers to achieve the role of teaching changes, there are Conducive to building a new teacher-student relationship.

For example, in the actual sports training, part of the movement of the structure and knowledge of the more difficult to grasp. For example, in taekwondo, there is an action in the air 360 degrees intends to push the cyclone action. This action is the need for long time training and masters the main points of the force, as well as the movement of the divertible skills to do a good job. And this difficult action training for students is undoubtedly a huge challenge. And in terms of the difficulties of knowledge, but also too esoteric, if the teacher's professional level of education or education and teaching level is slightly worse, may not be able to teach this action very good to the students. Even if the teacher is too strong must also be repeated through the watch action to get one of the essentials of action. And this time the teacher is no way to have too much time for an action to repeat the teaching, so that will delay the progress of the entire physical education. Therefore, the use of contemporary information technology, through multimedia software to some of these difficult to complete the action and the essentials, through a detailed explanation in the video, you can slow motion, fast forward or slow down and other functions to show it. Teachers can also explain it step 
by step, which can be more clear training direction, and as in the training part, it can be through the multimedia function, the action decomposition of the training. And when you watch the video with the students can see different people training video, so as to analyze and compare, ask questions, answer questions, and effectively promote students to analyze the ability to solve problems, is conducive to the further development of physical education and training.

In the modern information technology, the use of multimedia is one of the methods of effective optimization of sports training in contemporary sports teaching and training, which can stimulate the motivation and interest of students' sports training and help students to understand the concept of action and sports knowledge, which plays a very important role and role in contemporary physical education teaching [5].

\section{The Information Technology in Sports Training in the Teaching Mode of Innovation}

In the traditional physical education training, the main use of the teacher while speaking side of the demonstration, while the students are in the side to imitate. This traditional way of teaching with the social progress and changes in people's way of thinking has become increasingly lost its advantages. And this traditional teaching model is more to the teacher as the main body, and for the students, the more passive acceptance of knowledge, this state of learning, it is difficult to achieve the desired teaching purposes. And according to the study of educational psychology, learning motivation is the most realistic and most active factor is the interest of things. Therefore, the traditional concept of physical education teaching model ignores the principle of teaching and teaching principles, and the application of modern information technology and physical education, not only to a variety of different sports theoretical knowledge and skills points, difficulties are summarized, and through humor Humorous way, so that students in a pleasant atmosphere to absorb knowledge. Supervision of information technology applied to the training of physical education, making sports love to learn the content and teaching training to get constant innovation and improvement.

\section{Conclusion}

Information technology in sports education training can only be applied to the people gradually attention to it, for the current development of sports, is both an opportunity and a challenge. And how to use the new scientific and technological means to innovate a highly efficient, high level of sports training model is our long-term study of an important issue.

\section{References}

[1] Dong Shibiao. Study on the Application of Data Mining Technology in Juvenile Healthy Sports Behavior [J]. Modern Electronics Technique, 2017, (09): 112-114 + 120.

[2] Shen Yang. The modern information technology in vocational colleges in the application of physical education [J]. Contemporary Sports Science and Technology, 2017, (08): 156-157.

[3] Che Yimin. Design and implementation of sports video analysis system in sports training [J]. Modern Electronic Technology, 2017, (05): 70-73.

[4] Wang Senting. The network information technology in sports management application [J]. Contemporary sports science and technology, 2017, (06): $176+178$.

[5] Bai Haijun, Gao Yunli. Application of Computer Virtual Reality Technology in College Physical Training [J]. Journal of Heilongjiang August First Land Reclamation University, 2013, (03): $105-107+112$. 